\title{
Application of Cyanidin in Quantitative Estimation of Metals in Fish Samples
}

\author{
Josephine N. Ike1, Andrew A. Tyopine ${ }^{2 *}$ C. O. B. Okoye ${ }^{1}$ \\ ${ }^{1}$ Department of Pure \& Industrial Chemistry, University of Nigeria, Nsukka, Nigeria \\ ${ }^{2}$ Department of Chemistry/Biochemistry \& Molecular Biology, Alex Ekwueme Federal University, Ikwo, Nigeria \\ Email: *andrew.tyopine@funai.edu.ng
}

How to cite this paper: Ike, J.N., Tyopine, A.A. and Okoye, C.O.B. (2019) Application of Cyanidin in Quantitative Estimation of Metals in Fish Samples. American Journal of Analytical Chemistry, 10, 621-628. https://doi.org/10.4236/ajac.2019.1012043

Received: October 24, 2019

Accepted: December 2, 2019

Published: December 5, 2019

Copyright $\odot 2019$ by author(s) and Scientific Research Publishing Inc. This work is licensed under the Creative Commons Attribution International License (CC BY 4.0).

http://creativecommons.org/licenses/by/4.0/

\begin{abstract}
The use of cyanidin as a metallochromic agent in analyses of heavy metal is reported. Cyanidin is a ligand that was extracted from Gmelina arborea fruit and characterized. The cyanidin was used to form complexes with metals in five fish samples for the quantitative determination of $\mathrm{Cu}, \mathrm{Zn}, \mathrm{Ca}$ and $\mathrm{Mg}$. The optimum $\mathrm{pH}$ for absorbances of the cyanidin-metal complexes was observed at 5. Experimental results obtained using cyanidin were compared with analyses results obtained by Atomic absorption spectrophotometry (AAS) and both methods were evaluated using paired T-test to ascertain the suitability of cyanidin as metallochromic agent for the quantitative determination of heavy metals in fish samples. A null hypothesis that cyanidin method is a good alternative to AAS was accepted for the analyses of $\mathrm{Cu}$ and $\mathrm{Zn}$ ( $p>0.05)$. The paired T-test, however rejected the null hypothesis for the determination of $\mathrm{Ca}$ and $\mathrm{Mg}(\mathrm{p}<0.05)$. This study has provided a cheap, sensitive, rapid, simple and easy method for metal determination in analytical samples.
\end{abstract}

\section{Keywords}

Cyanidin, Metal Complexes, Gmelina arborea Fruit, Fish Samples, Atomic Absorption Spectrophotometry, Null Hypothesis

\section{Introduction}

Anthocyanins belong to plants whose pigments are water soluble [1] [2]. They are widely distributed in nature and their pigment shades range from red, purple and blue. They are found in flowers, fruits, vegetables and other parts of higher plants. Anthocyanins belong to the class of flavonoids and have a general structural formula of $\mathrm{C}_{6} \mathrm{C}_{3} \mathrm{C}_{6}$ [1] [3]. Anthocyanins are hydroxyl B-ring substituted 
flavonoids whose conjugated double bond has the ability to absorb light in the visible light wave band. Anthocyanins are unstable at neutral to slightly acidic media. This may be attributed to the hydration of flavylium cation that is responsible for the colourless pseudobase and so stability is usually achieved through the complexation of the pigment in solution [4] [5]. The ability of anthocyanins to complex especially with metals is primarily determined by its glycosylated structure [6].

Cyanidin (2-(3,4-Dihydroxyphenyl)-3,5,7-trihydroxychromenylium chloride) is a derivative of anthocyanin and is a chromic indicator that has been isolated from flowers of Hibiscus sabdariffa [7], red beet [1] and many others [3]. Cyanidin is a sensitive metallochromic indicator for detecting changes in UV-Vis absorption parameters as a result of its interaction with a plethora of metal ions. Ukwueze et al. and Okoye et al. have registered cyanidin complexes with $\mathrm{Pb}^{2+}$, $\mathrm{Cr}^{3+}, \mathrm{Cd}^{2+}, \mathrm{Zn}^{2+}, \mathrm{Co}^{2+}, \mathrm{Cr}^{3+}, \mathrm{As}^{3+}, \mathrm{Cd}^{2+}, \mathrm{Cu}^{2+}, \mathrm{Fe}^{2+}, \mathrm{Hg}^{2+}$ and $\mathrm{Ni}^{2+}$ in solution [8] [9] [10]. Ekere et al. also contributed to the list when he investigated cyanidin complexes with $\mathrm{Bi}^{2+}, \mathrm{Sn}^{2+}, \mathrm{Mn}^{2+}, \mathrm{V}^{3+}$ and $\mathrm{Se}^{2+}$ in mixed aqueous solutions [11].

An important feature of anthocyanins is their $\mathrm{pH}$ dependence and their structure in aqueous solutions is distinguished from other forms with variations in $\mathrm{pH}$ [12] [13]. This also favours stability of their complexes with metals [14] [15] [16] [17]. The oxidation state of metal ions is another important factor that plays a crucial role in the formation of anthocyanin-metal complexes [18]. The most common metals in anthocyanin complexes are $\mathrm{Sn}, \mathrm{Cu}, \mathrm{Fe}, \mathrm{Al}, \mathrm{Mg}$, and $\mathrm{K}$ [19]. The metal binding ability of anthocyanins presents a simple, sensitive, cheap, rapid and environmentally friendly approach/analytical tool for metal determination in environmental samples [8] [9] [10] [11]. Metal binding activity of anthocyanins is investigated via a variety of analytical techniques and to date UV-Vis spectroscopy is considered the most informative tool for the detection of anthocyanins [14]. Jangantakumar and Shukla [20] and Okoye et al. [10] have registered that spectral characteristics in visible wave bands as well as additional maximum absorption in the UV region are the most potent ways to monitor metal binding activities of anthocyanins. On the other hand AAS is known for its versatility, reliability, sensitivity and accuracy. It still has limitation such as the use of reagents that are not eco-friendly [21]. Considering the increase in metal concentration in the environment which may affect life of fish and other aquatic organisms and man through food chain, there is the need for metal monitoring of fish as a source of food to man. Therefore this work is aimed at developing cyanidin as an indicator from Gmelina arborea whose fruit is non-edible in Nigeria for the purpose analytical importance and further validating its suitability by comparing its performance with AAS.

\section{Experiments}

All reagents and fish samples used were purchased in local market and the reagents were analar grade. Fresh stock and standard solutions were used through- 
out the experiment. The metal ions were determined in fish samples using Uv-Vis spectrophotometer (Jenway 6405 model), AAS (210CGP Bulk scientific) and Elico $\mathrm{pH}$ meter.

\subsection{Pigment Extraction and Purification}

$500 \mathrm{~g}$ of Gmelina arborea fruits (see Figure 1) were washed under tap and rinsed with distilled $\mathrm{H}_{2} \mathrm{O}$. The fruits were separated from its seeds; ground and $400 \mathrm{~cm}^{3}$ of distilled $\mathrm{H}_{2} \mathrm{O}$ were added to the extract. The ground fruits were filtered using Whatman filter paper No. 1. The supernatant was concentrated to $300 \mathrm{~cm}^{3}$ and diluted with $100 \mathrm{~cm}^{3}$ conc. $\mathrm{HCl}$ and refluxed for 2 hours. The solution was allowed to cool until crystals began settling out. The solution was later put in the refrigerator to allow for more crystal formation. The crystals were filtered, recrystallized from hot methanol and air dried in the laboratory at room temperature. The crystals were stored in a dark sample bottle to avoid auto oxidation.

\subsection{Preparation of $\mathrm{pH}$ Buffers}

Buffer solutions of $\mathrm{pH} 1$ to 8 were prepared using $\mathrm{KCl}, \mathrm{HCl}, \mathrm{KHC}_{8} \mathrm{H}_{4} \mathrm{O}_{4}$, $\mathrm{KH}_{2} \mathrm{PO}_{4}$.

\subsection{Spectral Characterization of Crystals}

$5 \%$ solution of the purified crystals were prepared by dissolving $5 \mathrm{~g}$ of the crystals in methanol containing $0.01 \%$ conc. $\mathrm{HCl}$ and made up to $100 \mathrm{~cm}^{3}$ in a standard flask. $1 \mathrm{~cm}^{3}$ of this solution was diluted to $10 \mathrm{~cm}^{3}$ and its $\lambda$ max was determined spectrophotometrically in a $1 \mathrm{~cm}^{3}$ cuvette by scanning from $200-700 \mathrm{~nm}$.

\subsection{Determination of Optimum pH (pH opt) and of Crystal-Metal Complexes}

$5 \mathrm{~cm}^{3}$ of $5 \%$ crystal solution and $5 \mathrm{~cm}^{3}$ of standard solutions of a metal under study were introduced into 8 beakers and their $\mathrm{pH}$ values varied in aqueous phase from 1 to 8 using freshly prepared buffer solutions. The absorbance of each analyte in solution was read at the adjusted $\mathrm{pH}$. The $\lambda \max$ of the analyte metal was obtained from plot between $\mathrm{pH}$ and the absorbance of the analyte.

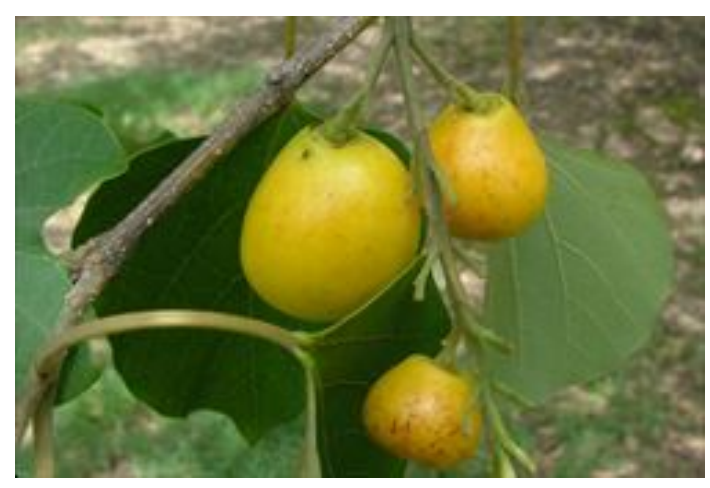

Figure 1. Mature Gmelina arborea fruit. 


\subsection{Determination of Wavelength of Maximum Absorption ( $\lambda$ max) of Crystal-Metal Complexes}

Fresh standard solutions of $\mathrm{Cu}^{2+}, \mathrm{Zn}^{2+}, \mathrm{Ca}^{2+}$, and $\mathrm{Mg}^{2+}$ were prepared at various concentrations ranging from 1.0 to $3.0 \mathrm{ppm} .5 \mathrm{~cm}^{3}$ of each standard solution were introduced into five sample bottles containing $5 \mathrm{~cm}^{3}$ of crystal solution and kept at pH5. After equilibration of the solutions, the absorbances of the crystal-metal complexes were recorded at maximum wavelength after scanning from 200 to $700 \mathrm{~nm}$.

\subsection{Sample Preparation and Analysis}

Five tilapia fish samples were dried at $105^{\circ} \mathrm{C}$ until constant weight was maintained. The dried fish samples were pulverized and weighed into porcelain crucibles. $1 \mathrm{~cm}^{3}$ conc. $\mathrm{HNO}_{3}$ was added to each crucible and ashed at $450^{\circ} \mathrm{C}$. The ashes were dissolved in $5 \mathrm{~cm}^{3} 1: 1 \mathrm{HCl}$ and samples transferred into $250 \mathrm{~cm}^{3}$ flask containing $1 \mathrm{~cm}^{3} 5 \%$ crystal solution at optimum $\mathrm{pH}$. The crystal-sample solutions were made up to mark with distilled water and analysed using UV-Vis spectrophotometer and AAS (210CGP bulk scientific).

\subsection{Statistical Analysis}

Paired T-test was used to determine significant variation between the developed method using the Gmelina arborea crystals and AAS. The null hypothesis $\left(\mathrm{H}_{0}\right)$ suggested that AAS and the developed method both produce comparable results for the heavy metals under study. This method was tested against the alternative hypothesis $\left(\mathrm{H}_{1}\right)$ which suggested otherwise therefore dismissing the suitability of the crystal as a metallochromic agent for heavy metals determination. The $\mathrm{H}_{0}$ was accepted when $\mathrm{p} \geq 0.05$ and $\mathrm{t}$ values were within critical values i.e. $-2.5706 \leq$ $\mathrm{t} \geq 2.5706$. The paired T-test was done with SPSS 21.0.

\section{Results and Discussion}

\subsection{Spectra Characterization of Purified Crystals from Gmelina arborea Extract}

The spectral data obtained from the analysis of the extract in comparison with literature values are shown in Table 1 . The values of $\lambda$ max of the extract matched with reported values that the crystals from Gmelina arborea extract were of cyanidin. The experimental values were not significantly variable when matched with those reported [22].

\subsection{Selection of Optimum pH at $\lambda$ max of Metal Ions}

The effect of $\mathrm{pH}$ on the formation of cyanidin-metal complexes was observed from a calibration curve. At various $\mathrm{pH}$ values, these cyanidin-metal complexes showed reproducible results. However, all the metal complexes showed prominent absorbances at $\mathrm{pH}=5$. In consideration of selectivity and sensitivity of the method, $\mathrm{pH}$ value of 5 was chosen as the optimum $\mathrm{pH}$ for the simultaneous determination of these metals complexes with cyanidin in aqueous media. 


\subsection{Analyses of Fish Samples Using the Cyaniding Complex}

The analyses results of metals from fish samples analysed with AAS and UV-Vis is shown in Table 2. The metal distribution was $\mathrm{Ca}>\mathrm{Mg}>\mathrm{Cu}>\mathrm{Zn}$ for AAs and $\mathrm{Cu}>\mathrm{Mg}>\mathrm{Zn}>\mathrm{Ca}$ when cyaniding method was used. These distribution patterns in the fish samples suggest different levels of the metals in the different environments the fishes habited. Table 3 shows the paired T-test of the significant differences in the methods and how they affect the $\mathrm{H}_{\mathrm{o}}$.

The mean concentration of $\mathrm{Zn}$ was $(1.5160 \pm 0.7071) \mathrm{ppm}$ from AAS and $(1.4814 \pm 0.7167) \mathrm{ppm}$ when analysed using cyanidin. Their mean difference was $(0.0342 \pm 0.0687)$. The difference was not significant $(\mathrm{p}>0.05)$ and $\mathrm{T}<2.5706$. $\mathrm{H}_{0}$ was accepted as summarised in Table 3 . Therefore $\mathrm{Zn}$ can be analysed using both AAS and cyaniding method. This may be said for $\mathrm{Cu}$ since there mean differences supported the $\mathrm{H}_{0}(\mathrm{p}>0.05,-2.5706 \leq \mathrm{t} \geq 2.5706)$ as shown in Table 3 . This can be attributed to the stable complexes they formed with cyanidin extracted from Gmelina arborea.

Table 1. Spectral characterization of purified crystals from Gmelina arborea extract [22].

\begin{tabular}{ccc}
\hline & UV region $(\lambda \max )$ & Vis region $(\lambda \max )$ \\
\hline Literature values & $282.5 \mathrm{~nm}$ & $530.6 \mathrm{~nm}$ \\
Experimental values & $282.7 \mathrm{~nm}$ & $530.0 \mathrm{~nm}$ \\
\hline
\end{tabular}

Table 2. Mean cyanidin and AAS results for metal analyses in $\mathrm{ppm}(\mathrm{n}=3)$.

\begin{tabular}{|c|c|c|c|c|c|c|c|}
\hline & Parameter & $\lambda \max$ & A & B & $\mathrm{C}$ & D & $\mathrm{E}$ \\
\hline \multirow[t]{4}{*}{$\mathrm{UV}-\mathrm{V}$ is } & $\mathrm{Zn}$ & 324.3 & $1.206 \pm 0.036$ & $1.263 \pm 0.037$ & $0.554 \pm 0.016$ & $2.364 \pm 0.070$ & $2.022 \pm 0.060$ \\
\hline & $\mathrm{Cu}$ & 296.7 & $2.701 \pm 0.081$ & $2.049 \pm 0.061$ & $1.508 \pm 0.045$ & $1.044 \pm 0.031$ & $2.703 \pm 0.081$ \\
\hline & $\mathrm{Mg}$ & 282.0 & $1.24 \pm 0.037$ & $0.624 \pm 0.0187$ & $1.377 \pm 0.0413$ & $1.265 \pm 0.0379$ & $0.141 \pm 0.00423$ \\
\hline & $\mathrm{Ca}$ & 279.6 & $0.331 \pm 0.009$ & $0.608 \pm 0.0182$ & $0.364 \pm 0.0109$ & $0.606 \pm 0.0181$ & $0.079 \pm 0.00237$ \\
\hline \multirow[t]{4}{*}{ AAS } & $\mathrm{Zn}$ & - & $1.21 \pm 0.0363$ & $1.42 \pm 0.0426$ & $0.58 \pm 0.0174$ & $2.37 \pm 0.0711$ & $2.02 \pm 0.0606$ \\
\hline & $\mathrm{Cu}$ & - & $2.80 \pm 0.084$ & $2.04 \pm 0.0612$ & $0.50 \pm 0.015$ & $1.02 \pm 0.030$ & $2.70 \pm 0.081$ \\
\hline & $\mathrm{Mg}$ & - & $4.80 \pm 0.144$ & $4.14 \pm 0.124$ & $2.95 \pm 0.088$ & $3.45 \pm 0.103$ & $4.69 \pm 0.140$ \\
\hline & $\mathrm{Ca}$ & - & $6.44 \pm 0.193$ & $8.88 \pm 0.266$ & $5.19 \pm 0.155$ & $9.52 \pm 0.285$ & $4.68 \pm 0.140$ \\
\hline
\end{tabular}

Table 3. Paired sample test $(\mathrm{p}=0.05, \mathrm{~N}=5)$.

\begin{tabular}{|c|c|c|c|c|c|c|}
\hline $\mathrm{S} / \mathrm{N}$ & Pair & Pair mean & Pair mean difference & $\mathrm{T}$ & $\mathrm{P}$ value & Decision on $\mathrm{H}_{0}$ \\
\hline 1 & $\begin{array}{l}\mathrm{Zn}^{*} \\
\mathrm{Zn}\end{array}$ & $\begin{array}{l}1.5160 \pm 0.7071 \\
1.4818 \pm 0.7167\end{array}$ & $0.0342 \pm 0.0687$ & 1.113 & 0.328 & Accepted \\
\hline 2 & $\begin{array}{l}\mathrm{Cu}^{*} \\
\mathrm{Cu}\end{array}$ & $\begin{array}{l}1.8120 \pm 1.0205 \\
2.0010 \pm 0.7321\end{array}$ & $-0.189 \pm 0.4604$ & -0.918 & 0.411 & Accepted \\
\hline 3 & $\begin{array}{l}\mathrm{Ca}^{*} \\
\mathrm{Ca}\end{array}$ & $\begin{array}{l}6.9420 \pm 2.1703 \\
0.3980 \pm 0.2205\end{array}$ & $6.5440 \pm 0.9698$ & 7.428 & 0.002 & Rejected \\
\hline 4 & $\begin{array}{l}\mathrm{Mg}^{*} \\
\mathrm{Mg}\end{array}$ & $\begin{array}{l}3.6060 \pm 1.5783 \\
0.9296 \pm 0.5303\end{array}$ & $2.6764 \pm 1.9278$ & 3.104 & 0.036 & Rejected \\
\hline
\end{tabular}

Metals with $\left({ }^{*}\right)$ are those analysed using AAS. 
The difference in mean of concentration of $\mathrm{Ca}$ in fish sample using cyanidin method and AAS was quite large $(6.5440 \pm 0.9698)$ compared to differences in means of $\mathrm{Zn}$ and $\mathrm{Cu}$. The difference was significant $(\mathrm{p}<0.05)$ and $\mathrm{T}$ value $>$ 2.5706. Therefore it did not support $\mathrm{H}_{0}$. This analogy applies to $\mathrm{Mg}$ whose difference in means was appreciably significant, $p<0.05$. This in turn produced T-test values greater than 2.5706 (7.428 for $\mathrm{Ca}$ and 3.104 for $\mathrm{Mg}$ ). Clearly statistics of $\mathrm{Ca}$ and $\mathrm{Mg}$ did not support $\mathrm{H}_{0}$. There large differences in mean may be suggesting a large shift in the UV region which explains absorption of light by unstable complexes of cyanidin with $\mathrm{Ca}$ and $\mathrm{Mg}$. Therefore the result indicates that cyanidin is not a suitable metallochromic agent for the estimation of $\mathrm{Ca}$ and $\mathrm{Mg}$ in the fish samples.

\section{Conclusion and Recommendations}

\subsection{Conclusion}

From the results obtained and the statistical evaluation of the data, cyanidin method and AAS were both good alternatives to analysing $\mathrm{Zn}$ and $\mathrm{Cu}$. Conversely, cyanidin method seems not a very good alternative to AAS in the quantitative determination of $\mathrm{Ca}$ and $\mathrm{Mg}$. The method has shown good sensitivity, reliability and easy preparation of the reagent compared with other existing extractive spectrophotometric determination methods.

\subsection{Recommendations}

This work recommends the following: firstly the authors have added Gmelina arborea as a source of cyanidin to published list of plants that contain cyanidin. There is plethora of plant sources yet to be identified and analysed for cyanidin. Such works should be done on plants that are yet to be explored to determine their analytical importance. This work has demonstrated the usefulness this method has on aquatic samples like fish. It is recommended that this method be used for metal analyses on other environmental samples such as soil, water, dust and plant tissues. As a work in progress, the authors are isolating other ligands contained in Gmelina arborea to determine their suitability in metal analyses.

\section{Acknowledgements}

The authors are grateful to Prof. C.O.B Okoye for his technical support in the course of the research.

\section{Conflicts of Interest}

The authors declare no conflicts of interest regarding the publication of this paper.

\section{References}

[1] Jaleel, K.A., Husain, A.M.S. and Angham, G.H. (2013) Anthocyanins in Red Beet Juice Act as Scavengers for Heavy Metal Ions Such as Lead and Cadmium. Interna- 
tional Journal of Science and Technology, 2, 269-274.

[2] Bodgan, S., Barbara, P. and Regina, D. (2008) Interaction between Cyaniding 3-Glucoside and $\mathrm{Cu}(\mathrm{II})$ Ions. Food Chemistry, 107, 1616-1622. https://doi.org/10.1016/j.foodchem.2007.10.037

[3] Regina, C., Diego, A.L., Daniel, M. and Elvira, G. (2016) Natural Pigments: Stabilization Methods of Anthocyanins for Food Applications. Comprehensive Reviews in Food Science and Food Safety, 16, 180-198. https://doi.org/10.1111/1541-4337.12244

[4] Yoshida, K., Mihoko, M. and Kondo, T. (2009) Blue Flower Color Development by Anthocyanins: From Chemical Structure to Cell Physiology. Natural Product Reports, 26, 857-964. https://doi.org/10.1039/b800165k

[5] Ellestad, G.A. (2006) Structure and Chiroptical Properties of Supramolecular Flower Pigments. Chirality, 18, 134-144. https://doi.org/10.1002/chir.20228

[6] Fossen, T. and Andersen, Ø.M. (2006) Spectroscopic Techniques Applied to Flavonoids. In: Andersen, Ø.M. and Markham, K.P., Eds., Flavonoids. Chemistry, Biochemistry and Applications, CRC Press, Boca Raton, FL, 37-142.

[7] Forsyth, F.G.C. and Sijmmonds, N.W. (1954) A Survey of the Anthocyanins of Some Tropical Plants. Proceedings of the Royal Society of London, B142, 549. https://doi.org/10.1098/rspb.1954.0043

[8] Ukwueze, N.N., Nwadinigwe, C.A., Okoye, C.O.B. and Okoye, F.B.C. (2009) Potentials of 3, 31, 41, 5, 7-Pentahydroxyflavylium of Hibiscus Rosa-Sinensis L. (Malvaceae) Flowers as Ligand in the Quantitative Determination of $\mathrm{Pb}, \mathrm{Cd}$ and Cr. International Journal of Physical Sciences, 4, 58-62.

[9] Okoye, C.O.B., Okon, E.E., Ekere, N.R. and Ihedioha, J.N. (2012) Simultaneous UV-VIS Spectrophootometric Quantitative Determinations of Cyanidin Complexes of $\mathrm{Co}, \mathrm{Zn}, \mathrm{Cr}, \mathrm{Cu}$, and $\mathrm{Fe}$ ions in Mixed Aqueous Solutions. International Journal of Analytical Bio-Science, 3, 1662-1664.

[10] Okoye, C.O.B., Chukwuneke, A.M., Ekere, N.R. and Ihedioha, J.N. (2013) Simultaneous Ultravioletvisible (UV-VIS) Spectrophotometric Quantitative Determination of $\mathrm{Pb}, \mathrm{Hg}, \mathrm{Cd}, \mathrm{As}$ and $\mathrm{Ni}$ Ions in Aqueous Solutions Using Cyanidin as a Chromogenic Reagent. International Journal of Physical Sciences, 8, 98-102. https://doi.org/10.5897/IJPS12.670

[11] Ekere, N.R., Okoye, C.O.B. and Ihedioha, J.N. (2014) Novel Simultaneous Spectrophotometric Determinations of Bi (III), Sn (II), Mn (II), V (III) and Se (II) Ions in Mixedaqueous Solutions. Journal of Chemical and Pharmaceutical Research, 6, 5-8.

[12] Arroyo-Maya, I.J, Campos-Terán, J., Hernández-Arana, A. and McClements, D.J. (2016) Characterization of Flavonoid-Protein Interactions Using Fluorescence Spectroscopy: Binding of Pelargonidin to Dairy Proteins. Food Chemistry, 213, 431-439. https://doi.org/10.1016/j.foodchem.2016.06.105

[13] Chung, C., Rojanasasithara, T., Mutilangi, W. and McClements, D.J. (2015) Enhanced Stability of Anthocyanins Based Color in Model Beverage Systems through Whey Protein Isolate Complexation. Food Chemistry, 76, 761-768. https://doi.org/10.1016/j.foodres.2015.07.003

[14] Trouillas, P., Sancho-García, J.C., De Freitas, V., Gierschner, J., Otyepka, M. and Dangles, O. (2016) Stabilizing and Modulating Color by Copigmentation: Insights from Theory and Experiment. Chemical Reviews, 116, 4937-4982. https://doi.org/10.1021/acs.chemrev.5b00507

[15] Pina, F., Melo, M.J., Laia, C.A., Parola, A.J. and Lima, J.C. (2012) Chemistry and Applications of Flavylium Compounds: A Handful of Colours. Chemical Society 
Reviews, 41, 869-908. https://doi.org/10.1039/C1CS15126F

[16] Buchweitz, M. (2016) Natural Solutions for Blue Colors in Food. In: Carle, R. and Schweiggert, R.M., Eds., Handbook on Natural Pigments in Food and Beverages. Industrial Applications for Improving Food Color, Woodhead Publishing, Sawston, Cambridge, 355-384. https://doi.org/10.1016/B978-0-08-100371-8.00017-8

[17] Zhao, C.L., Yu, Y.Q., Chen, Z.J., Wen, G.S., Wei, F.G., Zheng, Q., Wang, C.D. and Xiao, X.L. (2017) Stability-Increasing Effects of Anthocyanin Glycosyl Acylation. Food Chemistry, 214, 119-128. https://doi.org/10.1016/j.foodchem.2016.07.073

[18] Tachibana, N., Kimura, Y. and Ohno, T. (2014) Examination of Molecular Mechanism for the Enhanced Thermal Stability of Anthocyanins by Metal Cations and Polysaccharides. Food Chemistry, 143, 452-458.

https://doi.org/10.1016/j.foodchem.2013.08.017

[19] Cavalcanti, R.N., Santos, D.T. and Meireles, M.A.A. (2011) Non-Thermal Stabilization Mechanisms of Anthocyanins in Model and Food Systems: An Overview. Food Research International, 44, 499-509. https://doi.org/10.1016/j.foodres.2010.12.007

[20] Jayantakumar, M. and Shukla, V.J. (2014) Simultaneous UV-Visible Spectrophotometric Quantitative Determination of Heavy Metal Ions Using Calibration Method of Proposed Anti-Hyperglycaemic Formulation Using Cyaniding as a Chromogenic Reagent. International journal of Universal Pharmacy and Bio Sciences, 3, 329-336.

[21] Strong, F.C. and Martin, N.J. (1990) Rapid Determination of Zinc and Iron in Food by Flow-Injection Analysis with Flame Atomic-Absorption Spectrophotometry and Slurry Nebulisation. Talanta, 7, 11-718.

[22] Stephenson, A. (1998) Identification of Heavy Metals Found in Sample Collected from 10m Solvent Recovery and Hazard Water Indicator, San Lorenzo. Santa Green Peace Research Laboratories, University of Exeter, Exeter, UK, 100-145. 